\title{
NECROPOLÍTICA, RACISMO E SISTEMA PENAL BRASILEIRO I
}

NECROPOLITICS, RACISM AND THE BRAZILIAN CRIMINAL SYSTEM

AUGUSTO JOBIM DO AMARAL MELODY CLAIRE SCHMIDT VARGAS

RESUMO | O presente artigo tem por objetivo identificar os contornos do paradigma político da guerra operada no Brasil desde o dispositivo do racismo. Para além de constatar que a maioria das vítimas por homicídio no Brasil são negras, pretende-se identificar os elementos que alimentam historicamente a indiferença da população em geral diante de tal cenário. A partir da metodologia de revisão bibliográfica e de análise de dados indiretos, busca-se verificar como a mortalidade do sistema penal brasileiro é fomentada sob bases racistas, consolidando a exclusão do negro no lugar de exposição permanente à morte. Assim, desde o incremento neoliberal de uma necropolítica, percebem-se as dinâmicas que hoje orientam o genocídio como prática de governo.

PALAVRAS-CHAVE | Sistema Penal. Racismo. Neoliberalismo. Necropolítica.
ABSTRACT | The present article aims to identify the contours of the political paradigm of war operated in Brazil from the device of racism. In addition to finding that most homicide victims in Brazil are black, it intends to identify the elements that historically feed the indifference of the population in general in the face of such a scenario. Based on the methodology of bibliographic review and analysis of indirect data, it is sought to verify how the mortality of the Brazilian penal system is fomented on a racist basis, consolidating the exclusion of the black in the place of permanent exposure to death. Thus, from the neoliberal increment of a necropolitics, one can perceive the dynamics that today guide genocide as a practice of government.

KEYWORDS | Criminal System. Racism. Neoliberalism. Necropolitics. 


\section{INTRODUÇÃO}

niciamos o presente trabalho indo direto ao ponto que será abordado ao longo deste artigo, afirmando que vivemos em um Brasil que mata negros em larga escala. Se os números mostram que morrem mais negros do que brancos neste país, tal dado não é por acaso, nem se poderia cogitar qualquer coincidência, ainda que o mito da democracia racial pretenda conduzir o ideário para a crença de que todos temos iguais chances de usufruir dos recursos e privilégios sociais. O que está posto é uma política que provoca a morte direcionada, acometendo a população de cor desde a formação do país.

É por meio do sistema penal que o projeto genocida em curso vê a sua ferramenta fundamental. Para demonstrar isso, além das estatísticas fixadas, analisaremos as políticas historicamente praticadas pelo Estado brasileiro. Tais políticas, desde sempre, direcionam a um segmento específico da população sua face violenta.

A raça, no Brasil, é um critério de longevidade. Apoiando-se nas importantes considerações de Ana Luiza Pinheiro Flauzina (2008), o termo raça será explorado aqui como ferramenta política, pois, mesmo que haja considerável contestação em termos biológicos sobre sua existência, fato é que certas representações culturais continuam a pautar políticas governamentais e, sobretudo, lastrear processo de criminalização. Nesse cenário, a pergunta que pretende o trabalho perseguir e responder é: como o extermínio do povo negro sustenta-se e é aceito com profunda naturalidade até hoje?

Buscaremos dimensionar o impacto das políticas de morte na população negra. Além disso, pretendemos trazer os elementos que permitem compreender como se configura o cenário que autoriza a instauração das políticas de morte sem que haja qualquer enfraquecimento do poder estatal. Nesse sentido, será 
demonstrado o quanto o neoliberalismo, como racionalidade, permite a ressignificação do sujeito, que de vítima passa a culpado, de subjugado passa a fracassado.

Ainda, após indicar o que torna o indivíduo passivo diante do extermínio do outro, pretendemos demonstrar como essa realidade se desenha por meio da chamada necropolítica, que se estrutura em cenários de ausência de direitos, e tem o potencial de matar sem subterfúgios. Nesse contexto, pontuaremos de que forma o nosso período colonial foi o berço da necropolítica brasileira, que se impõe no país até hoje, nas diversas operações governamentais, cujo nome já indica sua natureza: guerra contra o tráfico e guerra contra a violência, por exemplo.

Nessa análise, buscamos, ainda que sem a mínima pretensão de esgotar o conteúdo, escovar o sistema penal "a contrapelo" (BENJAMIN, 1987), mostrando quão profundo e estruturante é o papel do racismo nessa ferramenta de controle do Estado. Desse modo, nosso objetivo maior é descrever, em alguma medida, como o dispositivo racial opera em termos de governo neoliberal de morte dos corpos negros.

\section{RACISMO E CRIMINOLOGIA NO BRASIL}

O Brasil alcançou, em 2016, a marca histórica de 30,3 homicídios a cada 100 mil habitantes (IPEA, 2018, p. 20). É a primeira vez que o Brasil atinge essa taxa, ficando entre os cinco primeiros países no ranking mundial. Nesse sentido, a pergunta mais importante, e que funda o presente artigo, é: por que a maioria das pessoas mortas são negras?

Essa questão coloca em evidência um Brasil dividido. Desde já, é importante deixar claro que o evento morte será abordado neste artigo em seu sentido mais amplo, indo muito além da retirada da vida e estendendo-se à morte política, à segregação social, ao estado de total rejeição e, nesse sentido, ao 
completo desprezo pela existência do outro (ALMEIDA, 2018).

Os dados coletados no Atlas da Violência 2018, ano-base 2016, mostram que, enquanto a taxa de homicídios entre as pessoas da raça negra é de $40,2 \%$, a taxa de pessoas brancas mortas não passa de 16,0\% (IPEA, 2018, p. 40). Segundo a mesma pesquisa, no período de uma década (2006 a 2016), enquanto a taxa de homicídios aumentou em $23,1 \%$ entre a população negra, a de não negros diminui em 6,8\% (IPEA, 2018, p. 40), o que indica que o nível de violência, além de ter crescido, se reorganizou, potencializando-se contra o povo de pele escura.

As estatísticas mostram que as condições e a expectativa de vida de determinados indivíduos são condicionadas a critérios. Esses critérios são definidos e alimentados pelo Estado, que tem o sistema penal como ferramenta de controle e morte em massa (ZAFFARONI, 2001). Trazendo para o contexto brasileiro, os números acima evidenciam o funcionamento de um projeto de Estado de caráter genocida, voltado contra a população negra no país (FLAUZINA, 2008).

A efetividade da prática genocida é demonstrada nos números relacionados ao grupo social mais vulnerável à violência: os homens negros. Segundo o Índice de Vulnerabilidade Juvenil à Violência, publicado em 2017, referente ao ano de 2016, jovens negros do sexo masculino entre 15 e 29 anos têm, em média, 2,71 chances a mais de morrer por homicídio do que os jovens brancos.

Quando se fala em homicídio de mulheres, a cor também exerce sua influência. Segundo o Atlas da Violência de 2018, a taxa de homicídios é de 5,3 mulheres negras a cada 100 mil, sendo que, em dez anos (2006-2016), esse índice teve um aumento de $15,4 \%$. Em flagrante contraste, a taxa de homicídios de mulheres não negras é de 3,1, revelando uma queda de $8 \%$ ao longo da mesma década (IPEA, 2018, p. 51).

No que diz respeito ao genocídio do povo negro, a atua- 
ção da polícia é bastante representativa: o Anuário Brasileiro de Segurança Pública (2017, p. 6), revela que 4.222 pessoas foram mortas em decorrência da ação policial e, dentre elas, $76,2 \%$ são negras. O número de habitantes negros no Brasil, considerando-se pretos e pardos, no mesmo ano em que ocorreu a pesquisa, representava $54,9 \%$ da população (IBGE, 2017), o que mostra o evidente descompasso entre os índices, e afasta qualquer discurso que prega a proporcionalidade desses números e uma suposta normalidade desse cenário.

Estabelecendo um paralelo, somente na cidade de São Paulo, no ano de 2014, 64\% dos mortos em decorrência da ação policial eram negros, sendo que a população negra na capital correspondia a $31 \%$ do total. Valendo-se dos dados do Censo Demográfico de 2010 para a obtenção de uma taxa aproximada, constata-se que, a cada 100 mil habitantes, quatro brancos foram mortos por policiais, enquanto o número de vítimas negras chegou a 11 no mesmo período (SINHORETTO; SCHLITTLER; SILVESTRE, 2016, p. 24).

Para entendermos os números que mostram o espaço dispensado ao negro no Brasil, é importante compreender, de antemão, o papel do sistema penal nessa realidade. Isso porque, desde sua estruturação no país, o sistema penal serviu como ferramenta que tornou possível o genocídio do povo negro, a partir das práticas que buscaram, desde o início da nossa história, "coordenar os corpos, conformá-los ao trabalho compulsório e, finalmente, naturalizar o lugar de subserviência" (FLAUZINA, 2008, p. 57). Dessa forma, ficaria garantida a exploração da força de trabalho que teve (e ainda tem) importância fundamental para a economia brasileira desde a sua formação (SCHWARCZ; GOMES, 2018).

Na lógica de exploração máxima do trabalho negro, fomos o país que mais escravizou e por mais tempo. Segundo Luis Felipe de Alencastro (2018), do século XVI ao XIX, mais precisamente 
até 1850 , quando o tráfico negreiro foi oficialmente extinto, o Brasil foi o país da América que mais traficou escravizados africanos. Em 1888, quando foi assinada a Lei Áurea, o Brasil era o único país do ocidente que ainda mantinha o sistema escravocrata (SCHWARCZ; GOMES, 2018).

À medida que o mercado açucareiro se expandia, maior era a demanda por força de trabalho. Nesse contexto, o tráfico africano de escravizados oferecia um volume de mão de obra que se encaixava perfeitamente ao cenário econômico do país (SCHWARCZ; GOMES, 2018). Desse modo, o trabalho negro transformou-se no recurso vital para o surgimento da economia brasileira. Celso Furtado (2007) classificou o trabalho escravo como "condição de sobrevivência", salientando que, sem o sistema escravagista, o colonizador europeu estaria limitado à produção para próprio consumo.

A economia brasileira não só ultrapassou o nível de subsistência, como foi muito além. Explorando o trabalho oriundo de mãos negras até a última gota nas lavouras brasileiras, os colonizadores formaram uma elite brasileira excepcionalmente rica (FURTADO, 2007). A economia açucareira e o povo escravizado cresciam juntos. Em cerca de 14.910 viagens pelo Atlântico, 4,8 milhões de africanos foram aprisionados e transportados para o Brasil, o que significa $46 \%$ do total de escravizados desembarcados no mundo (SCHWARCZ; GOMES, 2018).

A consequência do tráfico nessas proporções resultou em uma população negra que, às vésperas da abolição da escravatura, chegava a, aproximadamente, 5,7 milhões de pessoas. Em 1872 , no primeiro censo nacional do Brasil, o número de negros libertos chegava a 4,2 milhões, enquanto ainda existiam $1,5 \mathrm{mi}-$ Ihões de escravizados. O povo negro livre representava $43 \%$ da população brasileira, que, à época, era de, aproximadamente, dez milhões de pessoas (SCHWARCZ; GOMES, 2018).

Em um país em que metade da população se encontrava 
em situação de profunda desigualdade, o negro tornou-se uma presença incômoda. Afinal, o grupo que dirigia os rumos do país não estava disposto a rediscutir os ajustes pré-estabelecidos, que pressupunham distinções e violência (FLAUZINA, 2008). Seriam, portanto, necessárias ferramentas específicas de controle desse grande contingente. Até porque, esse povo gigante alimentava, de forma permanente, na sociedade branca, o medo de possíveis revoltas, que acabariam com o status quo há muito tempo estabelecido (SILVA; VALENÇA; MELLO, 2017).

O negro passa a ser visto como algo que ia além da figura do forasteiro, pois aquele que antes havia sido subjugado e mantido em lugar apartado da sociedade, agora estava livre, simbolizando uma ameaça à ordem e, nesse sentido, um inimigo comum (MORRISSON, 2012). Segundo Mbembe (2017), mais do que ver o negro como o forasteiro, existe uma impossibilidade de enxergar nele um vínculo humano, o que sustenta os discursos de animalização (macaco, sujo, burro). Além disso, essa visão sobre o povo negro permite uma espécie de pacto coletivo tácito, no qual, para esse segmento, é dispensado um espaço periférico na sociedade, onde pode ser colocado em prática um controle não oficial, desvinculado da legalidade (DUARTE, 1998).

O controle exercido pelo sistema penal vinha, muito antes da abolição, servindo como um braço do interesse privado (ZAFFARONI et al., 2003). Por meio do controle dos grupos alvo, a polícia atendia aos interesses de senhores e coronéis locais, os quais, em troca, garantiam a nomeação de funcionários protegidos, em uma relação que tornava bastante sutis as fronteiras entre as esferas pública e privada (SILVA; VALENÇA; MELLO, 2017).

À medida que a presença negra começou a tornar-se uma ameaça no espaço público, o Estado passou a reforçar as políticas penais direcionadas aos escravizados e alforriados. Segundo Nilo Batista (2004), em linhas gerais, o negro era o mesmo que 
um objeto perante o ordenamento jurídico imperial. Contudo, aos olhos do Direito Penal, ele era um indivíduo. Isso significa dizer, que era na esfera penal que o negro tinha um lugar, sendo visto como um agente punível e capaz das condutas que formam os estereótipos em torno da raça.

No mesmo sentido, conforme art. $6^{\circ}$ da Constituição Federal de 1824, os escravizados não eram reconhecidos como cidadãos (BRASIL, 1988). Contudo, embora não fossem vistos como sujeitos de direitos, já eram percebidos como a maior "clientela" do sistema penal. No período que vai de 1810 a 1821, sob o comando do Major Vidigal, a Guarda Real de Polícia, criada no Rio de Janeiro, em 1809, tinha uma população carcerária de $80 \%$ formada por escravizados e $19 \%$ por ex-escravizados. Isso significa que $99 \%$ dos presos eram negros (HOLLOWAY, 1997, p. 52).

Como forma de manutenção do controle e da limitação do acesso aos espaços públicos, os municípios também produziam leis, punindo a "deambulação", as manifestações religiosas ou culturais (BATISTA, 2006), a reunião de pessoas de cor, a venda de bebidas alcoólicas a negros e a realização de festas e batuques (MAIA, 2001). Além disso, eram rotineiros os encarceramentos pelo crime de vadiagem, as perseguições às capoeiras e a demolição de cortiços urbanos (CHALHOUB, 2012).

Os artigos publicados no país ao longo das campanhas abolicionistas demonstram a mentalidade que estava se formando na época, a qual viria a conduzir o projeto genocida mantido até hoje. Segundo Celia Maria Azevedo (1987), no período que cerca a abolição, o negro era visto como alguém que, por não ter nenhuma renda, poderia "preferir" a vadiagem. Nesse sentido, estavam autorizadas penas severas para coibir essa conduta, vista como uma tendência.

Com o fim da escravidão e o plano estatal de entrega dos postos de trabalho aos imigrantes vindos da Europa, estava criado 
o plano social que condenaria o contingente negro à marginalidade. O término da escravidão, visto, até o fim, com resistência pelas elites, veio acompanhado do descaso do poder vigente a respeito do que aconteceria com os 1,5 milhões de escravizados libertos. Sem emprego e renda, a situação de vulnerabilidade da imensa população de ex-escravizados foi não só ignorada, mas utilizada como discurso para fundamentar o estereótipo do negro vadio e de má índole (AZEVEDO, 1987).

Somos, portanto, um Brasil que estruturou o seu sistema penal a partir da punição de condutas diretamente relacionadas ao seu público alvo. Zaffaroni (2003) refere que as chamadas "agências de criminalização secundária" (policiais, promotores, advogados, juízes e agentes penitenciários), responsáveis por fazer cumprir a lei penal, por sua limitada capacidade operacional, são obrigados a agir de forma seletiva. Assim, o sistema penal foi concebido para criminalizar apenas um grupo selecionado, embora a criminalidade esteja presente em todos os segmentos (ANDRADE, 2003).

Se não passa de uma utopia querer punir todas as condutas criminosas, mais difícil ainda seria proteger da violência todos que necessitam. Zaffaroni (2003) explica que essa seleção não incide apenas sobre os criminalizados, mas, também, sobre os vitimizados. Em outras palavras, o sistema penal seleciona quem vai punir e quem vai proteger. Como veremos mais adiante, essa lógica coordenada de proteções e punições - o fazer viver e deixar morrer - materializa a política de controle e massificação dos corpos, o chamado "biopoder" (FOUCAULT, 2005).

Além disso, a seletividade assume uma aparência de "generalidade" à medida em que o sistema penal vai expondo a figura estigmatizada ao público (ZAFFARONI et al., 2003). Cabe retomar, aqui, o fato de que os estereótipos foram construídos pelo próprio sistema penal, e a exposição desses estigmas, a partir da exibição do indivíduo punido, confirma e reforça a ima- 
gem negativa, que é disseminada pelos meios de comunicação. Após incontáveis repetições dessa lógica, os estigmatizados, constantemente apontados como o lado negativo da sociedade, acabam por serem vistos como os "únicos delinquentes" que cometem os "únicos delitos".

Assim, surge a questão: como manter um grupo que representava quase metade da população do país em um sistema de controle tão repressivo por tanto tempo? Nesse ponto, cabem algumas palavras sobre o papel do "mito da democracia racial", um movimento intelectual inaugurado por Gilberto Freyre, em 1933, com a publicação da obra "Casa Grande e Senzala" (1990). Com um discurso sofisticado, as ideias iniciadas por Freyre conseguiram recriar a relação entre brancos e negros, jogando uma cortina de fumaça sobre o passado escravagista e, ao mesmo tempo, sobre o racismo (FLAUZINA, 2008).

Abdias do Nascimento (2016) refere que a relação amigável entre as raças pretendia esconder a "benevolência" que se mostrava nas mutilações físicas e morte causadas pelas punições e torturas, ou até mesmo a morte originada pelo desapego do negro à sua própria vida, o fenômeno chamado "banzo". Em última análise, esse aparato ideológico orientou a interpretação da história. Nas palavras de Flauzina, "não há o que discutir quanto à nossa forma de lidar tanto com a escravidão quanto com o racismo: suavizamos a primeira e negamos o segundo" (2008, p. 47).

Talvez o ponto mais perverso do mito da democracia racial seja a blindagem que seus discursos deram ao âmbito institucional, ao fazer com que o negro incorporasse os estereótipos reproduzidos pelo sistema penal como parte de si mesmo (FLAUZINA, 2008). Com isso, foi retirada do Estado a responsabilidade pelo genocídio, e transferida para o negro, que seria o causador do seu próprio fracasso. O racismo passa a ser assunto do âmbito privado, e se exterioriza de forma velada, acobertada pela ilusória 
igualdade de direitos. Ao se exteriorizar, o racismo é visto como um tabu, passando por todos os mecanismos de negação, que atribuem ao preconceito causas alheias à raça (nível econômico, educação, rixa, etc.) (SCHWARCZ, 1998).

Nesse cenário, os mesmos estereótipos reproduzem-se até hoje, a cada abordagem policial, em uma lógica que adota a "repressão antecipada dos presumidamente suspeitos" como meio para a manutenção da ordem (WANDERLEY, 2017). Indo mais a fundo, a partir do que já descrevemos como a lógica do sistema penal, concluímos que sua função é perseguir aqueles classificados como "suspeitos" a partir de critérios e estigmas que ele mesmo cria e reproduz. Esses critérios são claros e diretos: jovem negro, sexo masculino e com sinais indicativos de que pertence à periferia (WANDERLEY, 2017).

O resultado dessa persecução penal se reflete na imensa massa carcerária que coloca o Brasil na terceira posição com maior número de pessoas presas no mundo (BRASIL, 2018). O Relatório INFOPEN, atualizado até junho de 2016, mostra que, das 493.145 pessoas cuja raça foi possível identificar no sistema prisional, 64\% são negras (BRASIL, 2017, p. 32). Essa é mais uma porta para o genocídio, pois as condições dos presídios brasileiros e o atendimento à saúde prestado nesses lugares faz com que uma pessoa encarcerada tenha três vezes mais chances de morrer do que alguém que está fora do sistema prisional (CONECTAS DIREITOS HUMANOS, 2018).

Ao analisarmos a população carcerária em conjunto com a pesquisa nacional por domicílios, realizada em 2015 pelo IBGE (2016), constatamos que a população negra maior de 18 anos atingia um patamar de $52,95 \%$ naquele ano no país, índice inferior ao percentual de negros encarcerados. A partir da reflexão sobre o número de negros dentro e fora dos presídios, é possível perceber para quais grupos o sistema penal endereça suas práticas punitivas. 
O número de encarcerados negros reforça os rótulos a partir de uma imagem deturpada, divulgada incessantemente pela mídia. As capturas são publicizadas por meio de mensagens de conteúdo positivo, enquanto o indivíduo capturado é exposto com mensagens de teor negativo. Constrói-se um discurso em que é irrelevante o crime praticado ou a existência de condenação. Esse tipo de mensagem genérica se dissemina, reforçando entre a população a ideia de que as pessoas presas cometeram os mais graves crimes (homicídios, estupros, etc.), quando, na verdade, a maioria dos encarcerados cometeram delitos que são "obra tosca da criminalidade" (ZAFFARONI et al., 2003), como no caso do Brasil, onde a maioria da população carcerária cometeu os crimes de roubo, tráfico de tóxicos e furto (BRASIL, 2017, p. 43).

Os estigmas que definem o grupo mais vulnerável e suscetível à morte estendem-se a todos os segmentos sociais, inclusive extensiva esta vulnerabilização à própria polícia, que também é vítima da violência. Temos, portanto, uma instituição que mata, mas também que morre, e os policiais que mais morrem são aqueles subjugados à lógica do genocídio promovido pelo Estado. Isso porque a polícia, surgida no país no período imperial, era formada por indivíduos que faziam parte dos grupos criminalizados, ou seja, desempregados, ex-escravizados, descendentes de escravizados, mestiços, artesãos e biscateiros. Isso fazia com que o poder instituído não raramente visse o efetivo policial como responsável pela indisciplina (HOLLOWAY, 1997).

Assim, as baixas patentes e os baixos cargos da polícia são o alvo não só de desvalorização, mas também de mortandade. São 453 profissionais da segurança pública que perderam a vida em 2016 (FÓRUM BRASILEIRO DE SEGURANÇA PÚBLICA, 2017, p. 27). O índice mostra que a violência se reproduz em todos os espaços, e que o mito do policial herói é apenas mais um discurso, que tenta esconder e glorificar a prática genocida que recai sobre os mais vulneráveis, independentemente do papel que eles exerçam. 


\section{NEOLIBERALISMO: O SISTEMA PENAL DA CATÁSTROFE}

Nesse engenhoso sistema, é fundamental apontar a relação que existe entre a desigualdade social e o racismo no Brasil. A ideia de que a concentração de renda em nada tem a ver com a cor da pele é mais um recurso discursivo, que converge com a ilusão da harmonia entre as raças. O fato é que, após o fim da escravidão, os negros não tinham mais utilidade no futuro do país, e o imigrante europeu passaria a ser a representação do progresso e da raça superior (AZEVEDO, 1987).

Com o imigrantismo, mais do que reformular o sistema de mão de obra da economia agroexportadora, foi possível instalar um projeto eugênico de embranquecimento da raça (NASCIMENTO, 2016). O desejo de eliminar a população afrodescendente do país justifica-se pelo sonho do surgimento da raça brasileira, apoiando-se em uma lógica que veremos com mais detalhes ao falar sobre políticas de morte.

Diante do desejo de atrair a vinda massiva de europeus ao Brasil, desde 1880 , foram oferecidas todas as vantagens para estimular a imigração europeia, a começar pelo pagamento das passagens para vinda dos colonos ao país. Além disso, eram muitos os que apoiavam a ampliação das políticas legislativas que incentivassem a ida de imigrantes para o meio urbano, a fim de que os negros fossem expulsos para o âmbito rural (AZEVEDO, 1987).

Por meio de uma verdadeira política de cotas (que hoje causa polêmica), os imigrantes europeus receberam benefícios governamentais concedidos a eles e suas famílias, que garantiram uma fonte de sustento e prosperidade na nova pátria (GOLIN, 2014). Em flagrante contraste, não foi desenvolvida nenhuma política voltada à integração social do ex-escravizado, que, progressivamente, ia sendo abandonado na periferia por um governo indiferente, que via na abolição da escravatura o grande acerto 
de contas. Nas palavras de Abdias do Nascimento: "atirando os africanos e seus descendentes para fora da sociedade, a abolição exonerou de responsabilidades os senhores, o Estado, e a igreja" (2016, p. 80).

Esse cenário mostra que a desigualdade no Brasil não foi um resultado da pura e simples acumulação de renda por um grupo, mas, sim, a consequência de uma política de exclusão do negro dos meios de trabalho e renda. A desigualdade, portanto, fundou-se sobre a raça, em um Estado que promoveu políticas públicas voltadas à concessão de benefícios para uns, enquanto virava as costas à miséria que cercava outros.

Nesse sentido, à medida que se tornaram escassos os recursos para sobrevivência desse segmento da população, as alternativas de vida foram se estreitando. Com poucas opções dentro da legalidade, principalmente no caso de um sistema penal que foi concebido para controlar justamente aquelas atividades que estão na esfera da informalidade, o povo negro, facilmente, tornou-se a maior "clientela" do sistema punitivo (FLAUZINA, 2008).

A desigualdade, que, no Brasil, se estruturou sobre o critério da raça, permanece com os mesmos paradigmas. Dados divulgados pelo IBGE apontam que o rendimento médio real habitualmente recebido pelos pardos e negros equivale, respectivamente, a $55,6 \%$ e $54,9 \%$ do rendimento recebido por não negros (IBGE, 2017). Além disso, no terceiro trimestre de 2017, a taxa de desocupação dos negros foi de $14,6 \%$, enquanto no caso dos brancos o índice foi de 9,9\% (IBGE, 2017).

No mesmo período em análise, o IBGE (2017) apontou que $66 \%$ dos trabalhadores domésticos do país são representados por negros e pardos. Por outro lado, os cargos mais valorizados (como aqueles ligados à administração pública, defesa, seguridade social, educação, saúde, serviços sociais, informação, comunicação, atividades financeiras e administrativas) são ocu- 
pados, na sua maioria, por brancos. Os números mostram de que forma é delineado o mecanismo que move os negros para a marginalidade, em um cenário em que se abrem poucas portas de fuga desse grande jogo de exclusão.

A lógica neoliberal vem trazer novos elementos a esse contexto, fornecendo ferramentas para que o sistema penal potencialize suas políticas genocidas quanto àqueles que já estão à margem. De fato, o neoliberalismo vai muito além de uma teoria econômica, uma vez que acaba condicionando outras esferas. Antoine Garapon (1999) defende, por exemplo, uma justiça neoliberal, que deve avaliar o impacto que uma decisão judicial irá causar para as grandes corporações antes de analisar a questão de mérito sob os parâmetros da justiça.

Dardot e Laval (2016), por sua vez, entendem o neoliberalismo como uma verdadeira nova "razão de mundo", algo que vai muito além do modelo econômico, pois equivale a uma nova racionalidade, que aprofunda sua influência ao mais íntimo nível das relações sociais. Rubens Casara (2017) aponta que a teoria neoliberal, surgida a partir da crise econômica da década de 30, não se confunde com a racionalidade neoliberal, surgida entre os anos de 1980-1990, que passa a exercer influência sobre o Estado e cada indivíduo, à medida que são adotadas práticas de dominação dos corpos (controle externo e de exploração do outro) e das mentes (controle interno e exploração-de-si), a partir do uso do biopoder e do psicopoder.

Biagini e Peychaux (2016) tratam do tema a partir da proposta do neologismo "neuroliberalismo", que denomina uma racionalidade que é resultado da completa introjeção do modelo de mercado, e que provocou o desfazimento dos laços antes existentes entre os indivíduos. Segundo os autores, trata-se de um sistema político suicida, na medida em que sustenta um "egoísmo virtuoso" em cada indivíduo, o qual passa a sustentar o próprio sucesso no fracasso alheio. Nesse contexto, a formação 
das comunidades torna-se um movimento social impossível. Além disso, o individualismo extremado leva à propagação de discursos que condenam toda a ação que pretenda proteger direitos fundamentais, em uma lógica que traduz um ataque à própria existência. Os autores concluem que "tal como a criança que crê que ninguém a vê porque taparam os olhos, a fantasia ideológica da propaganda neoliberal se aboca a negar a realidade e insistir em práticas legitimadoras de um sistema anti-humanitário". (BIAGINI; PEYCHAUX, 2016, p. 159).

Nesse cenário, a dimensão da lógica "todos contra todos" invade nossos relacionamentos em níveis profundos. Dardot e Laval (2016) referem que até mesmo os mais desfavorecidos disputam entre si, acreditando em uma razão do mundo que apresenta discursos com aparente plausibilidade para justificar o aprofundamento das desigualdades. O conceito de empresa passa a fazer parte da individualidade dos sujeitos, o que autoriza cada um a desprender-se de qualquer senso coletivo e da política no seu verdadeiro sentido.

Uma vez que a racionalidade neoliberal transforma o indivíduo em um "empresário de si mesmo" (DARDOT; LAVAL, 2016), a dinâmica da concorrência é internalizada em um novo patamar. Nesse contexto, a alteridade é demonizada, e aqueles que não se encaixam ou não concordam com a lógica de mercadoria (que coloca felicidade e consumo como sinônimos) passam a não ter valor. Esse processo, segundo Rubens Casara (2017), corresponde ao esvaziamento do indivíduo (que é massificado, conforme convém ao mercado) e ao desaparecimento do "outro" (que perde completamente o espaço dentro da ditadura do Eu). Esse Eu que vê como irrelevante aquilo que se refere ao coletivo e que, portanto, está fora do que diz respeito ao próprio desempenho.

Os efeitos danosos do neoliberalismo alcançam um novo nível após a crise de 2008, com uma série de medidas adotadas 
por diversos países, buscando salvar o capitalismo. As decisões tomadas pelo governo norte-americano, após a ocorrência da bolha imobiliária, deram o tom das posturas austeras que criaram uma reação em cadeia por outros países do ocidente, incluindo o Brasil. Diversas políticas foram adotadas para salvar os atores que compõem o mercado financeiro e, como consequência, as camadas mais pobres da população passaram a ser mais oprimidas (GONÇALVES; MARTA, 2018).

A mudança no fluxo dos recursos, saindo das mãos da população para a reacumulação no setor financeiro privado, foi viabilizada pela precarização e pela privatização dos serviços públicos que, agora, seriam prestados àqueles que pudessem pagar. Assim, aos indivíduos que, eventualmente, não tivessem condições de arcar com os custos das suas necessidades, restava recorrer às dívidas bancárias ou suportar a privação dos meios de vida (ALMEIDA, 2018).

Tais práticas seguiram a lógica que marca esse sistema governamental, o qual vê, no desmantelamento do Estado do Bem-Estar Social, o seu fortalecimento. Para isso, adota-se o discurso falacioso de que a livre concorrência garantirá a circulação dos recursos entre todos. Biagini e Peychaux (2016) referem que as frases "o Estado não é a solução, mas sim o problema", ou "diminuir o Estado é aumentar a nação" são os grandes slogans do repertório neoliberal. Nesse sentido, o imperativo é ofuscar o Estado até o mais próximo de seu desaparecimento, extinguindo, assim, o poder de tributação, pouco importando se essa tributação tem, dentre outros fins, a função de custear serviços básicos a quem não pode pagar.

Nessa lógica, a escassez financeira da população e o alargamento das diferenças sociais seriam fatores que enfraqueceriam o poder vigente, não fosse a capacidade que o sistema neoliberal tem de se auto fortalecer. Dardot e Laval (2016) referem que as crises, ao contrário de causar a retração dessa 
política, promovem sua expansão. Isso se tornou possível a partir do momento em que algumas atividades políticas e, em última análise, o próprio jogo democrático, transformou-se em elemento em desuso.

Indo além, Silvio de Almeida (2018) pontua que a continuação desse sistema será baseada na redução progressiva do regime democrático. Casara (2017) afirma que o sistema neoliberal alcançou a hegemonia e, a partir desse ponto, foi abandonada a noção de Estado Democrático de Direito, que se resume a uma terminologia útil apenas para recursos discursivos.

Sendo o neoliberalismo um modelo político que se baseia na expropriação de bens como meio de concentração de riquezas (GONÇALVES; MARTA, 2018), o autoritarismo e a violência são as ferramentas que viabilizam essa dinâmica. Em outras palavras, a ação agressiva do Estado garante a lógica expropriatória e de auto desmanche (DARDOT; LAVAL, 2016).

Augusto Jobim do Amaral (2018) refere que o Estado, na lógica neoliberal, torna-se o garantidor das práticas de violência que surgem no cenário em que o sujeito é ressignificado como empresa individual. $\mathrm{O}$ autor ainda refere que, longe de ser uma ideologia ou política econômica, o neoliberalismo representa uma racionalidade de governo, uma vez que corresponde a uma teoria totalizante dos modelos de mercado, regulando a segurança e a liberdade. Nesse sentido, ele molda comportamentos sociais, determinando o tipo de relacionamento entre os indivíduos. Essa regulação acontece por meio do símbolo do perigo, sendo o governo o grande "gestor do perigo" (AMARAL, 2018, p. 522).

Nesse contexto, são priorizadas as funções do Estado ligadas à polícia e à justiça, para que seja garantida a "segurança". Wacquant (2010) fala da "ansiedade difusa", causada pela confusão entre a insegurança e sensação de insegurança, que alimenta um temor desconectado da realidade. Nessa lógica, o Estado manipula esse sentimento, que se torna verdadeira ferra- 
menta política. Assim, ele reproduz (por meio da mídia e de seus agentes) um discurso fundado no medo, que amplia a sensação de insegurança, desencadeando, nos indivíduos, a necessidade de proteção, ainda que à custa da brutalidade estatal. É o caso, por exemplo, das pessoas que moram em áreas nobres do Rio de Janeiro, que se sentem mais inseguras do que aquelas pessoas que vivem nas regiões com mais altos índices de criminalidade e que estão expostas aos mais diversos tipos de violência, seja física, subjetiva ou estrutural (CASARA, 2017).

Nesse cenário, as alegorias da "guerra contra o tráfico" ou "guerra contra o crime" consolidam o mito do inimigo comum e fornecem o disfarce perfeito à violência promovida pelo Estado, na medida em que justificam as políticas de controle que vitimizam os grupos alvo, sob o argumento de que tais medidas, ainda que genocidas, são fundamentais para a garantia da segurança do indivíduo (FRANCO, 2014). Dessa forma, o Estado se coloca como protetor, capaz de coibir o mal que, na realidade, é propagado por ele mesmo, progressivamente, conforme vão se expandindo os meios repressivos (GONÇALVES; MARTA, 2018).

$A$ racionalidade neoliberal, somada à crise política que o país enfrenta, abriu as portas para os atores que viabilizam a expansão desses meios repressivos, sob a promessa de vencer a luta do bem contra o mal. Casara (2017) aponta que, nesse contexto, fortalecem-se fenômenos como o "messianismo" e a "demonização":

Esse "salvador da pátria" pode ser um juiz midiático ("messianismo jurídico", para utilizar a expressão da cientista política espanhola Esther Solano), um militar saudosista dos regimes de exceção ("messianismo bélico") ou um empresário de sucesso (“messianismo empreendedor"). Não importa: entre pessoas autoritárias, os heróis sempre serão auto- 
ritários. Ligada à identificação de um messias está a demonização daqueles que pensam diferente ou que não possuem valor dentro da lógica que se extrai da razão neoliberal (CASARA, 2017, p. 182-183).

Ana Flauzina (2008), em um olhar criminológico, afirma que o neoliberalismo inaugura uma nova fase do sistema penal. Para ela, esse aparelhamento ideológico significa uma sofisticação do poder de controle, a partir do momento em que, por meio de uma nova retórica discursiva, ampliam-se as desigualdades, mantendo-se a raça como fator principal de hierarquização. Isso significa que os efeitos da lógica neoliberal no Brasil, que acentuam as distâncias e alimentam o medo coletivo, recaem, especialmente, sobre o negro, pela via dos estereótipos que a ele são atribuídos. Ou seja, o negro segue vinculado aos papéis sociais que lhe foram reservados ao longo da história do país: da ameaça, do intruso e do inimigo.

O contexto da disputa individual e da concorrência vem contribuir para o aprofundamento dessa estigmatização, uma vez que estimula a desclassificação do outro e o desprezo pela alteridade (MORRISSON, 2012). O preconceito racial torna-se, portanto, a opção adotada pelo Estado para uma integração social possível, à medida que traz uma alternativa à concorrência generalizada, por meio da abertura de uma via de eliminação dos grupos indesejados, dos quais o povo negro faz parte (ALMEIDA, 2018).

Segundo Casara (2017), os mecanismos punitivos destinam-se àquelas pessoas com "pouca utilidade" na lógica neoliberal. Essa prática resulta no extermínio dos estigmatizados, por meio de uma seleção binária que separa o amigo do inimigo, absolve e condena. Nesse cenário, o apoio social ao genocídio se forma a partir de manifestações polarizadas, que ocorrem, especialmente, nos espaços onde não cabe qualquer proble- 
matização (redes sociais ou meios de comunicação de massa). Assim, aqueles que não se comportam da forma esperada pelo sistema neoliberal (seja porque não produzem, não consomem ou não entram no jogo da concorrência de todos-contra-todos) enfrentam a resposta penal, que bate, diariamente, à porta para tomar a liberdade ou a vida.

Essa lógica binária, que separa os bem-sucedidos dos fracassados e alimenta a concorrência entre os indivíduos, ocorre não somente entre opressores e oprimidos, mas dentro do próprio grupo subjugado. Replica-se, diariamente, o que Flauzina (2008, p. 63) apontou como o projeto que marcou o período posterior à abolição no Brasil e partiu em pedaços o segmento negro, adotando um "estatuto desumanizador, que gera seres fraturados, capazes de negar a humanidade em seu próprio meio". Assim, segue em andamento o mecanismo que coloca em lados rivais pessoas que estão no mesmo grupo de vulnerabilidade, e que formam o mesmo alvo do sistema punitivo.

Segundo Gustavo Oliveira (BORGES; AMARAL; PEREIRA, 2014, p. 73), "na circunstância concreta, aquele que mais sofre na pele a luta contra o terror e o rótulo de ameaça à segurança nacional é a figura abstrata do 'estrangeiro'”. No Brasil, a figura do estrangeiro recai sobre o negro, visto como aquele que nunca pertenceu a este lugar, e que deveria ter sido enviado de volta para a África assim que a escravidão foi abolida (AZEVEDO, 1987).

É por meio das alegorias neoliberais que se opera o distanciamento do espaço entre «nós» e «eles». Nesse contexto, o Estado, que animaliza e estigmatiza a população negra, agora, encontra, na racionalidade neoliberal, o potencial discursivo para a permanência de suas políticas de morte. Associa-se aqui o termo "política" à palavra morte, porque é no poder de matar que o Estado constrói sua prerrogativa de atuação e a relativa estabilidade da soberania, traduzindo o que se denomina necropolítica (MBEMBE, 2017). 


\section{NECROPOLÍTICA: O DIREITO DE MATAR SOBERANO}

Já vimos como a sociedade aceitou, de forma passiva, a segregação e a aniquilação do povo negro. Mas como a pauta genocida foi transmitida do poder imperial até os governos do período moderno, com a manutenção das práticas de extermínio dessa raça? Especialmente no contexto brasileiro, em que o mito da democracia racial está infiltrado em todas as relações, como se sustenta um contexto em que um jovem negro é morto a cada 23 minutos (ONU, 2017)?

Com a chegada do século XIX, ocorre uma mudança nos meios de controle dos indivíduos como forma de reafirmação do poder em diversos países ocidentais. A antiga dinâmica não dava mais conta de uma sociedade em alta expansão demográfica e industrial. Michel Foucault (2005) refere que a modernidade é marcada pelo desenvolvimento de práticas estatais que passam a tomar o controle da vida como forma de domínio dos corpos e mentes. Assim, foi exercendo o domínio sobre as chances de vida dos indivíduos que o Estado promoveu a manutenção da soberania. A esse modelo o autor dá o nome de "biopoder".

Isso significa que, fazendo uso do biopoder para ditar os comportamentos no espaço de vida, o Estado mantém a sua condição de existência. Em sua análise, Foucault (2005) faz uma importante distinção que cabe ser reproduzida aqui: o biopoder é a lógica que centra as ações do Estado na manipulação dos indivíduos por meio dos diversos aspectos que cercam a vida (educação, saúde, previdência, os diversos sistemas de seguros, etc.). Nesse paradigma, o gerenciamento da morte não caberia de forma natural, ou seja, seria impossível ao Estado exercer o poder de morte dentro da lógica que privilegia a vida. É nesse momento, segundo o autor, que o racismo assume um novo papel na história, sendo a chave para o extermínio daquele segmento considerado degenerado dentro dos parâmetros biológicos instituídos. 
Por meio do racismo, portanto, o poder estatal consegue realizar um verdadeiro corte social, separando aquilo que pode viver daquilo que deve morrer. Nesse cenário, a raça é o critério para valoração dos sujeitos. Silvio de Almeida (2018) aponta que, desde o lluminismo, a sociedade se estruturou por meio da classificação e a comparação entre os seres. Nesse sentido, com o biopoder, a raça passou a ser um critério evolucionista e tornou-se o fundamento capaz de justificar a coexistência de dois cenários antagônicos promovidos pelo mesmo Estado: a liberdade e a igualdade universais em contraponto à escravidão e à sujeição.

Mbembe (2017) refere que, para além do parâmetro de maior ou menor valor do indivíduo, o racismo tem o papel de reforçar nas pessoas os ideais iluministas ao criar um distanciamento das fronteiras entre "eu" e "ele". Essa cisão estimulou sentimentos que se associam aos ideais de razão, autonomia e liberdade, especialmente importantes na lógica da modernidade. O racismo, portanto, é o elemento que, ao mesmo tempo serve como critério de hierarquia, é a ferramenta que reaparelha o direito de matar no Estado moderno. Ao demarcar as distâncias entre os indivíduos, o racismo estabelece lados opostos, na medida em que a raça de um grupo ameaça a qualidade da raça do outro. Nesse sentido, Foucault (2005, p. 305) afirma que "a morte do outro não é simplesmente a minha vida, na medida em que seria minha segurança pessoal; a morte do outro, a morte da raça ruim, da raça inferior (ou do degenerado, ou do anormal), é o que vai deixar a vida em geral mais sadia; mais sadia e mais pura".

Indo mais fundo no conceito de biopoder trazido por Foucault (2005), Mbembe (2017) afirma que o Estado, hoje, sustenta suas práticas de controle e manutenção do poder em políticas de morte, ao que ele chama de "necropolítica". Segundo ele, esse novo modelo é o resultado da união entre o biopoder, 
estado de exceção e estado de sítio, sendo que a raça permanece como o meio que liga esses três elementos.

Para Agamben (2003), o poder de matar do Estado fundase no espaço vazio de direitos que existe entre o estabelecimento da norma e sua aplicação, revelando a vulnerabilidade da vida nua, privada dos mecanismos estatais de proteção. Nesse espaço em que, segundo o autor, está o estado de exceção, é possível estabelecer um estado de emergência permanente e, nesse contexto de supressão de direitos, tornar possível a eliminação de qualquer grupo que não esteja integrado ao sistema político.

O estado de exceção é o cenário em que não existem garantias legais aplicadas no caso concreto. Nesse contexto, o poder estatal se impõe de forma violenta no dia a dia, envolto pela blindagem da normalidade que o torna invisível. Silvio de Almeida (2018) refere que é o racismo que permite um conformismo social com relação à violência, autorizando "que se naturalize a morte de crianças por "balas perdidas" (...), que se exterminem milhares de jovens negros por ano, no que vem sendo denunciado há anos pelo movimento negro como genocídio" (ALMEIDA, 2018, p. 94).

Ainda sobre o estado de exceção, Mbembe (2017) refere que as colônias são espaços, por excelência, onde puderam ficar suspensos quaisquer direitos e garantias. Em um país que ainda guarda muito das raízes coloniais, o Brasil reproduz, cotidianamente, em toda a sua estrutura penal, a relativização e a suspensão dos direitos daqueles que são o alvo do seu sistema, o qual, seletivamente, privilegia de um lado e oprime de outro. Na mesma linha, Zaffaroni (2001) refere que o sistema penal foi concebido para que a legalidade processual não seja aplicada e, assim, se opere o poder de forma arbitrária e seletiva, focada nos grupos vulneráveis.

É possível identificar, nas raízes coloniais do nosso país, a alternância entre a biopolítica e a necropolítica. Segundo Flauzina (2008), a biopolítica foi o recurso para a elaboração do discurso 
que vigeu no país após a abolição da escravatura e foi capaz de manter o cenário de aniquilação do negro. Nesse sentido, quando o fim da escravidão era inevitável, as ações do Estado passaram a voltar-se para a vida, a partir de um argumento de controle que transformou a massa liberta em um problema não mais político, mas sim biológico.

A vida, portanto, precisava ser preservada, melhorada. Sob esse pretexto, mais do que manter o negro sob controle, seria preciso extingui-lo, como uma forma de depuração e fortalecimento da raça. Teorias como as de Nina Rodrigues (2011) e as declarações de membros do poder na época (SKIDMORE, 2012) mostravam um rumo claro para o país: o do desaparecimento da presença negra como uma necessidade para a evolução e o equilíbrio social. Nesse contexto, o genocídio assume uma segunda via, própria do Brasil: a da extinção da raça pelo embranquecimento.

A necropolítica manifesta-se, no país, a partir do momento em que não é mais necessária a formulação de discursos voltados para a vida, com o fim de justificar a morte. Silvio de Almeida (2018) explica que o modelo de poder, no Brasil, sofrendo os reflexos do colonialismo, passou a não mais se sustentar no equilíbrio entre a vida e morte, mas sim no livre exercício do poder de matar ou de colocar o indivíduo em constante contato com o extermínio, em um cenário em que a "guerra, política, homicídio e suicídio tornam-se indistinguíveis" (ALMEIDA, 2018, p. 90).

Ao falar de políticas de morte, não nos restringimos ao contexto dos presídios brasileiros, mas a todos os cenários em que o Estado exerce o poder punitivo (seja por meio das ações do poder judiciário, dos agentes policiais ou da produção legislativa). Segundo Zaffaroni (2001), estamos lidando com uma gigantesca "instituição de sequestro". Nesse sentido, a prisão, as escolas, os hospitais e os quartéis seriam instituições de sequestro menores dentro de outra maior. Dessa forma, as condições peculiares que 
vêm do passado colonial, traduzindo-se na morte em massa e na radicalização da violência, não se resumiriam ao cárcere, mas ao sistema penal como um todo.

Retornando ao conceito de necropolítica trazido por Mbembe (2017), é relevante tratar aqui do terceiro elemento desse modelo, o estado de sítio. Trata-se daquele ambiente em que passam a ser rotineiramente adotadas as práticas que só seriam admissíveis em um contexto de extrema instabilidade social (MBEMBE, 2017). Nesse cenário, a sociedade legitima o Estado para realizar todas as violações de direitos necessárias ao combate do "mal". Em nome da defesa nacional, os agentes do sistema penal brasileiro, especialmente a polícia, "invadem moradias, realizam detenções sem ordem judicial, proíbem reuniões e manifestações públicas, (...) esquartejam, degolam, enforcam, fuzilam e ainda ocultam os corpos" (TADDEO, 2012).

Os permanentes estados de exceção e de sítio do período moderno são viabilizados pela alegoria do inimigo comum. Augusto Jobim do Amaral explica que:

O controle de circulação de imigrantes, minorias e daqueles que buscam asilo operacionaliza um novo campo de controle estabelecido na criação de imagens de novos inimigos, campo este que transborda para além de fronteiras. Os subterfúgios do terrorismo, do crime organizado, do tráfico de drogas ou inúmeras outras construções narrativas de controle emergencial permitem que regras de exceção materializem suas tendências de se tornarem permanentes através do exercício da exclusão definitiva de determinados grupos de sujeitos (AMARAL, 2018, p. 538). 
Em um contexto em que a luta pelo acesso ao capital pauta as relações humanas e fundamenta a hierarquização entre os indivíduos, a proteção da vida tem direta ligação com o controle das contingências. Segundo Mbembe (2017), a natureza das nossas necessidades e a contingência são os parâmetros que determinam o cenário de liberdade que criamos. Nessa lógica, nossa liberdade se mede no nível em que nossas necessidades são atendidas e, para tanto, a contingência, elemento natural da vida, deve estar a nosso favor. Assim, o mundo precisa ser moldado, e tudo aquilo que eleva as imprevisibilidades deve ser extinto.

Diante disso, determinados grupos alvo são apresentados como uma verdadeira ameaça ao equilíbrio esperado das contingências, e o medo desses indivíduos passa a ser alimentado pelo Estado, a fim de que sejam legitimadas práticas genocidas. Nesse cenário, o medo produz e se alimenta de uma "violência biopolítica", em uma lógica que gera inimigos de forma incessante, tornando legítima a guerra no ambiente doméstico e justificando um estado de exceção que não tem fim (SCHMITT, 2015). São produzidos discursos recorrentes, disseminados pelos meios de comunicação de massa, pregando que o inimigo não está mais além das delimitações territoriais do Estado, mas no ambiente interno, em um processo que delimita novas distâncias e fronteiras (SCHMITT, 2015). Nesse sentido, o clássico arsenal de guerra é substituído pela atuação da polícia, e o inimigo se redefine, deixando de ser aquele situado fora do país e passando a ser aquele que vive no próprio território.

Segundo Carl Schmitt (1992), o inimigo não é aquele que simboliza o adversário, mas sim aquele que detém os atributos do inimigo público, que ameaça um grupo de pessoas unidas por um elemento em comum. Por esse motivo, para ser inimigo, basta que o sujeito seja existencialmente diferente ou desconhecido por esse conjunto de pessoas que se sentem conectadas pelo 
mesmo contexto. Nessa lógica, a inimizade se eleva a um grau de conflito, que não mais se submete às regras do Estado de Direito. Esse tipo de cenário permite o assassinato de "Marielles" e "Amarildos", sem que tais barbáries ensejem qualquer reflexo negativo ao poder vigente.

Trata-se de um contexto em que os direitos são suspensos em caráter permanente em nome da proteção desses próprios direitos (SCHMITT, 2015). Wayne Morrison (2012) afirma que a soberania alimenta o mito do inimigo comum a partir do momento em que nega a hostilidade que existe em todos nós e a coloca "somente no outro", mostrando esse outro como alguém que merece ser tratado com violência e que, ao mesmo tempo, é imune a essa violência. Nesse contexto, o inimigo ganha poder e simboliza uma ameaça muito mais letal.

Carl Schmitt (2008) refere que o poder que o Estado concentra, um misto de controle da vida dos indivíduos e da prática de fazer guerra, permite que ele exija do sujeito a disposição para morrer e matar para combater a ameaça externa. A manutenção do poder soberano se justifica, portanto, na sua capacidade de declarar as guerras internas e, assim, manter o equilíbrio, que está sendo, constantemente, ameaçado pelos inimigos que ele mesmo produz.

A guerra contra o tráfico, declarada pelo Estado do Rio de Janeiro, é bastante ilustrativa para demonstrar as práticas estatais. Longe de combater a real fonte do comércio de drogas, ela atacou a fatia deste mercado correspondente ao varejo, que, sabidamente, não oferece qualquer ameaça ao poder instituído, e o eventual enfraquecimento dessa parcela do "negócio" não gera qualquer impacto no império do tráfico. Na realidade, a ação do Estado, sob o pretexto de combate à comercialização de drogas ilícitas, tornou possível a ocupação das favelas pelas UPPs (Unidades de Polícia Pacificadora), ampliando, assim, o controle estatal sobre os corpos e as mentes dos indivíduos que 
vivem nesses espaços (MARTINS; SANTOS, 2017).

A ocupação das favelas cariocas pelas UPPs traduz-se como uma das técnicas mais eficazes dos últimos tempos do uso do biopoder (MARTINS; SANTOS, 2017). Com um discurso que atribuiu à ocupação um caráter "humanista", a UPP prometia ser a ponte que traria condições de cidadania para dentro das favelas. Pretendendo parecer uma política de pacificação e promoção da liberdade, a UPP correspondeu ao controle penal irrestrito, imposto ao dia-a-dia dos moradores das favelas de forma violenta (FRANCO, 2014).

Em um ambiente onde o totalitarismo democrático está estabelecido (MARTINS; SANTOS, 2017), a eliminação dos indivíduos já é previamente justificada pela ameaça que o inimigo representa. Agamben (2010) refere que o totalitarismo moderno é comparável a uma "guerra civil legal", que permite o extermínio de grupos inteiros de pessoas, selecionadas conforme um sistema político que vê esses sujeitos como intrusos, com a validação da maior parte da sociedade, a qual aceita com naturalidade a gradual extinção desse segmento.

Essa naturalização da violência contra negros é o que permite chamar de estrutural o racismo no Brasil. Silvio de Almeida (2018) afirma que o racismo estrutural age no contexto da normalidade, mantendo vivos discursos que afastam tentativas mais consistentes para coibir as práticas racistas. Isso significa dizer que a visão estrutural (e estruturante) se expressa como uma forma de racionalidade, algo que vai muito além de uma interpretação simplista que venha a entender o preconceito como um desvio de caráter.

O racismo, como racionalidade no Brasil, é o que garante a continuidade do plano genocida. Uma pesquisa desenvolvida pela Secretaria Especial de Políticas de Promoção da Igualdade Racial (DATASENADO, 2012, p. 4), em conjunto com o Senado Federal, apontou que $55,8 \%$ das 1.234 pessoas entrevistadas, 
espalhadas por 123 municípios do país, concordaram com a afirmação de que "a morte violenta de um jovem negro choca menos a sociedade do que a morte violenta de um jovem branco".

Nesse caminhar, o genocídio segue seu curso, sem que a intencionalidade do sistema penal provoque qualquer reação maior. Dessa forma, os mecanismos que blindam as práticas racistas, promovidas por ações realizadas em todos os segmentos do sistema, seja pelo poder judiciário (SANTOS, 2015) ou por agentes policiais, promovem a manutenção das engenharias que pretendem a extinção da raça negra.

\section{CONSIDERAÇÕES FINAIS}

Os números mostrados neste trabalho mostram que não existem coincidências nos resultados das políticas de morte no Brasil. Ainda que as análises sejam segmentadas em gênero, idade ou localidade em que vivem no país, o número de pessoas brancas mortas não supera, em nenhum critério, o número de negros mortos. Vimos, também, que não só a morte, mas as condições de vida que expõem o sujeito à eliminação (desemprego, baixa renda e cárcere, por exemplo) estão mais presentes entre o povo não branco.

Ainda, demonstramos que o sistema penal é a grande ferramenta estatal para controle desse segmento desde o surgimento da polícia imperial. Em uma fusão do privado com o público, a sujeição do negro, realizada pelos Senhores no âmbito da senzala, era transferida às mãos da polícia, sob a tutela do Estado. Dessa forma, ao longo da história do nosso país, o sistema penal teve, no racismo, o elemento que justificou seu surgimento e sua existência.

Buscamos, dessa forma, expor, ao longo deste artigo, os elementos que montam, desde a formação deste país, o cenário que viabiliza a sujeição de não brancos e seu genocídio. Nesse 
sentido, a escravidão, instituição total que dita até hoje nossos comportamentos, firmou o terror que seria imposto aos corpos e às mentes do povo negro no Brasil e que inspiraria as práticas aplicadas pelas agências executivas da ditadura militar.

Apesar das atrocidades experimentadas nesse período da nossa história, ainda se mostram vivas as ideias que defendem um governo com "mãos de ferro", e que atribuem o declínio econômico e a criminalidade ao fim da ditadura. Assim, caminhamos em direção a uma cada vez maior criminalização e punição de condutas e, por outro lado, a uma crescente resistência às políticas de direitos humanos e ao debate político.

Vimos que essa tendência está inteiramente de acordo com a racionalidade neoliberal que redimensiona as relações interpessoais nos mais profundos níveis. Os dogmas neoliberais, ao redefinir as subjetividades, ampliam as distâncias e inserem a concorrência entre os indivíduos como condição inevitável para o sucesso. Nesse cenário, multiplicam-se os motivos para segregar o negro nos espaços a ele relegados desde o início da nossa história.

Ao ser responsabilizado pela própria sujeição e enquadrado nos estereótipos que correspondem ao inimigo, o povo negro pode ser exterminado sem maiores obstáculos. O negro, portanto, vive um contexto de permanente estado de exceção e sítio, elementos que traduzem a necropolítica.

Ainda que o sistema penal seja a grande "máquina" do projeto genocida, este artigo não tem por hipótese a reforma do sistema penal como solução para o fim das políticas de morte estatais fundadas no racismo. O racismo é elemento integrante do sistema penal desde sua constituição, em tamanha profundidade que seria inimaginável o atual sistema de controle sem ele. Nesse sentido, qualquer tentativa de proteção dos direitos do povo negro que passe pelo sistema punitivo que está posto apenas irá alimentar mais das mazelas que vivenciamos. E se o aparato penal abriga justamente 
o espaço em que o racismo tem uma de suas principais fontes de sustentação, o resguardo de direitos por esta via demonstra-se profundamente frágil. Quer dizer, noutros termos que as políticas de acesso igualitário a meios repressivos não devem servir como bandeira de luta para defesa dos grupos marginalizados.

Isso significa tomar um posicionamento crítico que contraponha os diversos discursos que colocam o negro na posição do inimigo, que mascaram ou minimizam toda a violência institucional sofrida sob argumentos de democracia racial. Como escrito, cabe refletir, incansavelmente, sobre os processos de extermínio que podem conduzir políticas estatais.

\section{REFERÊNCIAS}

AGAMBEN, G. Estado de Exceção. São Paulo: Boitempo, 2003.

AGAMBEN, G. Homo sacer: o poder soberano e a vida nua I. 2. ed. Belo Horizonte: UFMG, 2010.

\section{ALMEIDA, S. L. D. O que é racismo estrutural? Belo Horizonte: Letramento, 2018.}

AMARAL, A. J. D. Biopolítica e biocapitalismo: implicações da violência do controle. Veritas, Porto Alegre, v. 63, n. 2, p. 515543, maio-ago 2018.

ANDRADE, V. R. P. D. A ilusão da segurança jurídica: do controle da violência à violência do controle penal. Porto Alegre: Livraria do Advogado, 2003.

AZEVEDO, C. M. M. D. Onda negra, medo branco: o negro no imaginário das elites - século XIX. Rio de Janeiro: Paz e Terra, 1987. 
BATISTA, N. A violência do estado e os aparelhos policiais. Discursos Sediciosos. Crime, direito e sociedade, Rio de Janeiro, v. 2, n. 4, 1997.

BATISTA, N. Novas tendências do direito penal - artigos, conferências e pareceres. Rio de Janeiro: Revan, 2004.

BATISTA, N. Pena Pública e Escravismo. Capítulo criminológico: Revista de las Disciplinas del Control Social, v. 34, n. 3, p. 279-321, jul./sep. 2006.

BATISTA, V. M. O medo na cidade do Rio de Janeiro: dois tempos de uma história. Rio de Janeiro: Revan, 2003.

BENJAMIN, W. Magia e técnica, arte e política. Tradução de Sergio Paulo Rouanet. 3. ed. São Paulo: Brasiliense, 1987.

BIAGINI, H. E.; PEYCHAUX, D. F. O Neuroliberalismo e a ética do mais forte. Nova Petrópolis: Nova Harmonia, 2016.

BORGES, R. M. Z.; AMARAL, A. J. D.; PEREIRA, G. O. D. L. Direitos Humanos e Terrorismo. Porto Alegre: EDIPUCRS, 2014.

BRASIL. MINISTÉRIO DA JUSTIÇA. Há 726.712 pessoas presas no Brasil. Ministério da Justiça. Disponível em: https:// guiadamonografia.com.br/citacao-de-site-e-artigo-da-internet/. Acesso em: 14 set. 2018.

BRASIL. PRESIDÊNCIA DA REPÚBLICA. SECRETARIA DE GOVERNO. Índice de vulnerabilidade juvenil à violência 2017: desigualdade racial, municípios com mais de 100 mil habitantes. Organização das Nações Unidas para a Educação, 
a Ciência e a Cultura (UNESCO), 2017. Disponível em: http:// unesdoc.unesco.org/images/0026/002606/260661 por.pdf. Acesso em: 02 jul. 2018.

CARNEIRO, J. D. Cinco anos após a morte de Amarildo, família ainda aguarda indenização: "Estado tem que pagar por seu erro". BBC News Brasil, 2018. Disponível em: https:// www.bbc.com/portuguese/brasil-44790123. Acesso em: 26 out. 2018.

CASARA, R. R. R. Estado pós-democrático: neoobscurantismo e gestão dos indesejáveis. Rio de Janeiro: Civilização Brasileira, 2017.

CHALHOUB, S. A força da escravidão. llegalidade e costume no Brasil Oitocentista. São Paulo: Companhia das Letras, 2012.

CONECTAS DIREITOS HUMANOS. Dados. Carcerópolis, 2018. Disponível em: https://carceropolis.org.br/dados/. Acesso em: 30 set. 2018.

CONSELHO DE DIREITOS HUMANOS DAS NAÇÕES UNIDAS. Report of the special rapporteur on minority issues on her mission to Brazil. United Nations Human Rights, 2016. Disponível em: https://documents-dds-ny. un.org/doc/UNDOC/GEN/G16/021/35/PDF/G1602135. pdf?OpenElement. Acesso em: 02 jul. 2018.

DARDOT, P.; LAVAL, C. A nova razão do mundo: ensaio sobre a sociedade neoliberal. Tradução de Mariana Echalar. São Paulo: Boitempo, 2016. 
DATASENADO. Violência contra a juventude negra no

Brasil - pesquisa de opinião pública nacional. Brasília: Senado Federal, 2012.

DAVIS, A. Y. Are Prisons Obsolete? New York: Seven Stories, 2003.

DEPEN. Levantamento nacional de informações penitenciárias. Atualização - junho de 2016. Departamento Penitenciário Nacional, 02 Julho 2017. Disponível em: http:// depen.gov.br/

DEPEN/noticias-1/noticias/infopen-levantamento-nacional-deinformacoes-penitenciarias-2016/relatorio_2016_22111.pdf. Acesso em: 02 jul. 2018.

DUARTE, E. C. P. Criminologia e Racismo: introdução ao processo de recepção das teorias criminológicas no Brasil. Dissertação (Mestrado em Direito) - Universidade Federal de Santa Catarina. Florianópolis. 1998.

FLAUZINA, A. L. P. Corpo negro caído no chão: o sistema penal e o projeto genocida do Estado brasileiro. Rio de Janeiro: Contraponto, 2008.

FÓRUM BRASILEIRO DE SEGURANÇA PÚBLICA - FBSP. Anuário Brasileiro de Segurança Pública, São Paulo, n. XI, 2017.

FOUCAULT, M. A verdade e as formas jurídicas. Tradução de Roberto Cabral de Melo Machado e Eduardo Jardim Morais. Rio de Janeiro: NAU, 2002.

FOUCAULT, M. Em defesa da Sociedade. Tradução de Maria Ermantina Galvão. 4. ed. São Paulo: Martins Fontes, 2005. 
FRANCO, M. UPP - A redução da favela a três letras: uma análise da política de segurança pública do estado do Rio de Janeiro. Dissertação (Mestrado em Administração) Universidade Federal Fluminense. Niterói. 2014.

FREYRE, G. Casa-Grande \& Senzala. Rio de Janeiro: Record, 1990.

FURTADO, C. Formação Econômica do Brasil. 34. ed. São Paulo: Companhia das Letras, 2007.

GARAPON, A. O juiz e a democracia: o guardião das promessas. Tradução de Maria Luiza de Carvalho. Rio de Janeiro: Revan, 1999.

GOLIN, T. Os cotistas desagradecidos. Geledés, 2014. Disponível em: https://www.geledes.org.br/os-cotistasdesagradecidos/. Acesso em: 28 set. 2018.

GONÇALVES, G. L.; MARTA, M. R. D. A. Neoliberalismo autoritário em cinco atos. Le Monde Diplomatique Brasil, 2018. Disponível em: https://diplomatique.org.br/ neoliberalismo-autoritario-em-cinco-atos/. Acesso em: 28 set. 2018.

GUIMARÃES, A. S. A. Entrevista com Carlos Hasenbalg. Tempo Social, v. 18, n. 2, p. 259-268, nov. 2006.

HOLLOWAY, T. Polícia no Rio de Janeiro: repressão e resistência numa cidade do século XIX. Rio de Janeiro: FGV, 1997.

IBGE. Retrato das Desigualdades. IPEA, 2016. Disponível em: http://www.ipea.gov.br/retrato/indicadores.html. Acesso em: 02 jul. 2018. 
IBGE. Pretos ou pardos são 63,7\% dos desocupados, 2017. Disponível em: https://agenciadenoticias.ibge.gov.br/agencianoticias/2012-agencia-de-noticias/noticias/18013-pretos-oupardos-sao-63-7-dos-desocupados. Acesso em: 30 set. 2018.

IBGE. IBGE mostra as cores da desigualdade, 2017.

Disponível em: https://agenciadenoticias.ibge.gov.br/agencianoticias/2012-agencia-de-noticias/noticias/21206-ibge-mostraas-cores-da-desigualdade. Acesso em: 28 ago. 2018.

IBGE. Indicadores IBGE - Pesquisa Nacional por Amostra de Domicílios Contínua - Algumas características da força de trabalho por cor ou raça. Rio de Janeiro. 2017.

IBGE. População chega a 205,5 milhões, com menos brancos e mais pardos e pretos. Agência de Notícias IBGE, 2017. Disponível em: https://agenciadenoticias.ibge.gov.br/agencianoticias/2012-agencia-de-noticias/noticias/18282-pnad-cmoradores.html. Acesso em: 30 ago. 2018.

IPEA. Atlas da Violência 2018. Fórum Brasileiro de Segurança Pública e Instituto de Pesquisa Econômica Aplicada - IPEA. [S.I.]. 2018.

MAIA, C. N. Policiados: controle e disciplina das classes populares na cidade do Recife, 1865-1915. Tese (Doutorado em História) - Universidade Federal de Pernambuco. Recife. 2001.

MARTINS, F.; SANTOS, G. F. A. D. Estado, biopoder e UPPs: a vida nua das favelas e o genocídio negro enquanto projeto de Estado. Revista Brasileira de Ciências Criminais, São Paulo, v. 135, n. 25, p. 131-162, setembro 2017. 
MBEMBE, A. Políticas da Inimizade. Tradução de Marta Lança. Lisboa: Antígona, 2017.

MIRANDA, I. A necropolítica criminal brasileira: do epistemicídio criminológico ao silenciamento do genocídio racializado. Revista Brasileira de Ciências Criminais, São Paulo, v. 135, n. 25, p. 231-268, setembro 2017.

MORRISSON, W. Criminología, civilización y nuevo orden mundial. Tradução de Alejandro Piombo. Barcelona: Anthropos Editorial, 2012.

NASCIMENTO, A. O genocídio do negro brasileiro: processo de um racismo mascarado. São Paulo: Perspectivas, 2016.

NASCIMENTO, A.; VERÍSSIMO, J. O genocídio do negro brasileiro: processo de um racismo mascarado. São Paulo: Perspectivas, 2016.

ONU. Campanha Vidas Negras. Nações Unidas, 2017. Disponível em: http://vidasnegras.nacoesunidas.org/. Acesso em: 12 out. 2018.

PIRES, M. C. Economia brasileira: da colônia ao governo Lula. São Paulo: Saraiva, 2010.

RODRIGUES, R. N. As raças humanas e a responsabilidade penal no Brasil [online]. Rio de Janeiro: Centro Edelstein de Pesquisa Social, 2011. Disponível em: https://static.scielo.org/ scielobooks/h53wj/pdf/rodrigues-9788579820755.pdf. Acesso em: 14 out. 2018.

SANTOS, D. A tentativa de apagar a mente pensante de 
Marielle com 4 tiros não cessou sua luta. Huffpost Brasil, 2018. Disponível em: https://www.huffpostbrasil.com/danysantos/a-tentativa-de-apagar-a-mente-pensante-de-mariellecom-4-tiros-nao-cessou-sua-luta_a_23387608/. Acesso em: 26 out. 2018.

SANTOS, G. A. D. Nem crime nem castigo: o racismo na percepção do judiciário e das vítimas de atos de discriminação. Revista do Instituto de Estudos Brasileiros, n. 62, p. 184207, dezembro 2015.

SCHMITT, C. O conceito do político. Tradução de Alvaro Luiz Montenegro Valls. Petrópolis: Vozes, 1992.

SCHMITT, P. H. Espaço de exceção / a produção biopolítica do medo e do inimigo. In: GLOECKNER, R. J.; FRANÇA, L. A.; RIGON, B. S. Biopolíticas. Curitiba: iEA Academia, 2015. p. 223-237.

SCHWARCZ, L. M. Nem preto nem branco, muito pelo contrário: cor e raça na intimidade. In: SCHWARCZ, L. M. História da vida privada no Brasil: contrastes da intimidade contemporânea. São Paulo: Companhia das Letras, 1998.

SCHWARCZ, L. M.; GOMES, F. D. S. Dicionário da Escravidão e Liberdade - 50 textos críticos. São Paulo: Companhia das Letras, 2018.

SECRETARIA DE GOVERNO DA PRESIDÊNCIA DA REPÚBLICA. Relatório do Índice de Vulnerabilidade Juvenil à Violência 2017: desigualdade racial, municípios com mais de 100 mil habitantes. Fórum Brasileiro de Segurança Pública. São Paulo. 2017. 
SILVA, F. L. D.; VALENÇA, M. A.; MELLO, M. M. Policiados e policiais: dois tempos de uma história de criminalização. Revista Brasileira de Ciências Criminais, São Paulo, v. 135, n. 25, p. 97-128, setembro 2017.

SINHORETTO, J.; SCHLITTLER, M. C.; SILVESTRE, G. Juventude e violência policial no Município de São Paulo. Revista Brasileira de Segurança Pública, São Paulo, v. 10, p. 10-35, fev./mar. 2016.

SKIDMORE, T. E. Preto no branco: raça e nacionalidade no pensamento brasileiro (1870-1930). Tradução de Donaldson M. Garschagen. São Paulo: Companhia das Letras, 2012.

SOUZA, J. D. A tolice da inteligência brasileira: ou como o país se deixa manipular pela elite. São Paulo: Leya, 2015.

TADDEO, C. E. A guerra não declarada na visão de um favelado. São Paulo: Carlos Eduardo Taddeo, 2012.

UNITED NATIONS. Report of the Chair of the Working Group of Experts on People of African Descent. [S.I.], p. 21. 2014. (A/HRC/27/68/Add.1).

WACQUANT, L. INSEGURANÇA SOCIAL E SURGIMENTO DA PREOCUPAÇÃO COM A SEGURANÇA. Panóptica, n. 19, p. 198-213, julho 2010. Disponível em: https://app.vlex.com/\#BR. open/vid/222853557. Acesso em: 30 out. 2018.

WANDERLEY, G. A. Filtragem racial na bordagem policial: a estratégia de suspeição generalizada e o (des)controle judicial da busca pessoal no Brasil e nos Estados Unidos. Revista Brasileira de Ciências Criminais, v. 135, n. 25, set. 2017. 
ZAFFARONI, E. R. Em Busca das Penas Perdidas: a perda de legitimidade do sistema penal. Tradução de Romano Vania Pedrosa e Amir Lopez da Conceição. 5. ed. Rio de Janeiro: Revan, 2001.

ZAFFARONI, E. R. et al. Direito Penal Brasileiro: primeiro volume - Teoria Geral do Direito Penal. 2. ed. Rio de Janeiro: Revan, 2003.

$$
\begin{aligned}
& \text { Recebido em | 31/01/2019 } \\
& \text { Aprovado em | 08/04/2019 }
\end{aligned}
$$

Revisão Português/Inglês | Gabriela Marques Vilela

\section{SOBRE OS AUTORES | ABOUT THE AUTHORS}

\section{AUGUSTO JOBIM DO AMARAL}

Pós-Doutor em Filosofia Política pela Università Degli Studi di Padova - Itália. Professor dos Programas de Pós-Graduação em Ciências Criminais e em Filosofia da Pontifícia Universidade Católica do Rio Grande do Sul (PUCRS). E-mail: guto_jobim@ hotmail.com.

\section{MELODY CLAIRE SCHIMIDT VARGAS}

Graduanda em Direito pela Pontifícia Universidade Católica do Rio Grande do Sul (PUCRS). E-mail: melody.vargas@acad. pucrs.br. 